\title{
Motion-based predictive coding is sufficient to solve the aperture problem
}

\author{
Mina A Khoei, Laurent U Perrinet, Guillaume S Masson \\ From Twentieth Annual Computational Neuroscience Meeting: CNS*2011 \\ Stockholm, Sweden. 23-28 July 2011
}

It is still unclear how information collected locally by low-level sensory neurons may give rise to a coherent global percept. This is well demonstrated in the aperture problem both in visual or haptic senses. Experimental findings on its biological solution in area MT show that local motion measures are integrated to see the dynamical emergence of global motion information [1]. We develop a theory of spatio-temporal integration defined as implementing motion-based predictive coding. This takes the form of an anisotropic, context-dependent diffusion of local information [2]. Here, we test this functional model for the aperture problem in the visual and haptic low-level sensory areas.

In our model, spatial and motion information is represented in a probabilistic framework. Information is pooled using a Markov chain formulation, merging current information and measurement likelihood thanks to a prior on motion transition. This prior is defined so that it is adapted to smooth trajectories such as are observed in natural environments. This dynamical system favors temporally coherent features. Differently to neural approximations [3], we use a particle filtering method to implement this functional model. This generalizes Kalman filtering approaches that were used previously by allowing to represent non-gaussian and multimodal distributions.

We observe the emergence of mechanisms that reflect observations made at psychophysical and behavioral levels. First, the dynamical system shows the emergence of the solution to the aperture problem and show dependence to line's length [4]. Then,when presented with an object with a regular translation, the dynamical system grabs itsmotion independently of its shape and exhibits motion extrapolation. This shows that prediction is sufficient for the

\footnotetext{
* Correspondence: mina.khoei@incm.cnrs-mrs.fr Institut de Neurosciences Cognitives de la Méditerranée, CNRS, Université de la MéditerranéeÂA, 13402 Marseille Cedex 20, France

Full list of author information is available at the end of the article
}

dynamical build-up of information from a local to a global scale. More generally it may give insights in the role of spatio-temporal integration on neural dynamics in the emergence of properties that are accredited to low-level sensory computations.

Published: 18 July 2011

\section{References}

1. Smith MA, Majaj N, Movshon JA: Dynamics of pattern motion computation. In Dynamics of Visual Motion Processing: Neuronal, Behavioral and Computational Approaches. Springer;G. S. Masson and U. J. Ilg 2010:55-72.

2. Watamaniuk S, McKee S, Grzywacz N: Detecting a trajectory embedded in random-direction motion noise. Vision research 1995, 35(1):65-77.

3. Burgi PY, Yuille AL, Grzywacz N: Probabilistic motion estimation based on temporal coherence. Neural Computation. 2000, 12(8):1839-1867.

4. Castet $\mathrm{E}$, Lorenceau J, Bonnet $\mathrm{C}$ : The inverse intensity effect is not lost with stimuli in apparent motion. Vision Research 1993, 33(12):1697-1708.

doi:10.1186/1471-2202-12-S1-P279

Cite this article as: Khoei et al:: Motion-based predictive coding is sufficient to solve the aperture problem. BMC Neuroscience 201112 (Suppl 1):P279.

\section{Submit your next manuscript to BioMed Central and take full advantage of: \\ - Convenient online submission \\ - Thorough peer review \\ - No space constraints or color figure charges \\ - Immediate publication on acceptance \\ - Inclusion in PubMed, CAS, Scopus and Google Scholar \\ - Research which is freely available for redistribution

